\title{
INICIA EL 2022: OTRO AÑO DE CAMBIOS EN LA FORMA DE EDITAR REVISTAS CIENTÍFICAS
}

Start 2022: another year of changes in the way of publishing scientific journals

Wileidys Artigas*

https://orcid.org/0000-0001-6169-5297

\begin{abstract}
Como citar: Artigas, Wileidys. (2022). Inicia el 2022: otro año de cambios en la forma de editar revistas científicas. Telos: revista de Estudios Interdisciplinarios en Ciencias Sociales, 24 (1), Venezuela. (Pp. 3-5).

DOI: www.doi.org/10.36390/telos241.01
\end{abstract}

Los últimos dos años han significado en grandes cambios para el mundo editorial. Los editores de revistas científicas hemos tenido que adaptar nuestro trabajo a las nuevas realidades. La creación de redes y el trabajo con editores invitados han sido una de las formas de colaboración más utilizada, pues no solo ayuda a que la revista llegue a nuevos lugares, sino que también proporcionan una ayuda al editor en el desarrollo del proceso editorial, a su vez que genera la capacitación de los investigadores en el desarrollo del proceso, cuestión que no es despreciable en estos tiempos.

Conocer el proceso y desde la perspectiva del investigador ayuda a comprender y mejorar el propio proceso investigativo, ser más cuidadoso en sus propios trabajos y desarrollar además las labores de arbitraje que en suma ayudan a tener una visión más amplia del proceso.

El 2022 entonces sigue avisorandose con cambios para los editores de la revistas, no solamente en lo que ya habíamos expuesto en las ediciones del 2021 con respecto a la construcción de redes de trabajo y el fomento del trabajo con editores invitados desde otros paises para difundir el conocimiento y llegar a mayor cantidad de personas, sino también por el uso de nuevas formas de investigación, la modificación de los métodos de investigación adaptados a los tiempos de pandemia y el uso de nuevas tecnologías en todo el proceso de investigación que permitan el uso de la virtualidad como técnica de recolección de datos.

Todo esto implica seguirnos educando en metodología, ubicar y aprender nuevas formas para poder comprender nuevas tendencias y modelas y estar a la vanguardia

\footnotetext{
* Editora de la Revista. Doctora en Ciencias Sociales, mención Gerencia. Profesora e investigadora de la Facultad de Ciencias Económicas y Sociales de la Universidad del Zulia. Asesora en el área de Revistas Científicas de la Universidade Óscar Ribas de Angola. Correo electrónico: wileidys@hotmail.com; wileidys.artigas@urbe.edu.ve
} 
para poder revisar y admitir trabajos de investigación con nuevas propuestas metodológicas, sin que esto desmejore o desacredite la calidad del contenido; en pro de seguir aportando a las ciencias sociales.

En este sentido, y como en cada edición buscando seguir aportando al desarrollo de las ciencias sociales, en este número, se presentan 11 artículos y 1 reseña, que señalamos a continuación:

- Marketing estratégico odontológico en el marco del covid-19 en Ambato, Ecuador, de Andrés Sebastián Vasco Aguilera y Christian Andrés Barragan Ramírez.

- Burnout and Online Education: Adaptation and Validation of scale during Pandemic, de J. Patricia Muñoz-Chávez; Rigoberto García-Contreras y David Valle-Cruz.

- Buenas prácticas en emprendimientos lácteos, desde la economía social y solidaria en Biblián-Ecuador, de Ángel Esteban Muñoz Alvarez; Jorge Edwin Ormaza Andrade y Yonimiler Castillo Ortega.

- Innovación educativa y práctica pedagógica docente en instituciones educativas rurales en el Perú en tiempos de pandemia, de Edgar, MartínezHuamán; Edwin Daniel, Félix Benites y Rolando Alfredo, Quispe Morales.

- Intervención en docentes para el desarrollo de competencias psicomotoras en niños a nivel preescolar, de Pedro Erick Gastelum Acosta; Rigoberto Marín Uribe; Isabel Guzmán Ibarra y José Aldo Hernández Murúa-

- Organizaciones inteligentes y su incipiente incursión en la esfera turística. Una aproximación al estado del conocimiento, de Gema Simona Navarrete y Arlén Sánchez Valdés.

- Indicadores de confort relacionados con el desempeño académico de los estudiantes universitarios, de Luisana C. Bracho Pernalete.

- Estrategia de integración curricular: una mirada desde los talleres de odontología conservadora, de Mónica Cabrera; Alexandra Valarezo; Ilya Casanova y Tomás Quintero.

- Sociología del conocimiento, teoría de los campos y bibliometría, de Luis Ernesto Paz Enrique y Gloria Ponjuán Dante.

- Observação em psicologia escolar: vivências em uma instituição pública de ensino superior e médio, de Joanah Dal Mas dos Santos; Hildegard Susana Jung; Paulo Fossatti y Gisleine Verlang Lourenço.

- Desarrollo de la investigación: una mirada al basamento legal angolano, de Josefina Castillero Velásquez, Elexis Craib Díaz y Eurico Wongo Gungula. 
- Reseña del texto: Zellweger, Thomas (2017) Managing the Family Business: Theory and Practice. Edward Elgar Publishing, Por Roberto Carlos Dávila Morán.

Como puede observarse, la diversidad de trabajos en áreas de educación y gerencia principalmente, nos permiten seguir avanzando en cada uno de los campos del conocimiento en el que se desarrolla la revista, así mismo, la ampliación de recepción de trabajos en ingles y portugués nos permiten llegar a otros públicos.

Este año 2022 sigue planteando retos y desde ya estamos preparados para afrontarlos, pues seguimos educándonos en mejorar nuestros procesos y en seguir aprendiendo para ofrecer lo mejor a nuestros lectores, autores, arbitros y miembros. 